\title{
Prophylactic use of Parenteral Ketamine versus Ondansetron for Prevention of Shivering during Spinal Anesthesia in Hernia Surgeries
}

\author{
Nabila Mohammed Abdel Aziz Fahmy, Ayman Ibraheem Tharwat Sayed, Amr Hosny \\ Hamza Ali, Aya-tullah Hosny Kamal El-Deen Abd El-Aleem \\ Department of Anesthesiology, Intensive Care Medicine \& Pain Management, Faculty of Medicine, Ain Shams \\ University \\ Corresponding Author: Aya-tullah Hosny Kamal El-Deen Abd El-Aleem; Phone No.: (+2) 01127610348; E-mail: ayottoo@ hotmail.com
}

\begin{abstract}
Background: Perioperative shivering is a common complication in modern anesthesia. It's usually defined as readily detectable fasciculation or tremors of the face, jaw, head, trunk or extremities lasting longer than 15 seconds.
\end{abstract}

Aim of the work: Compare the anti-shivering effect of parentral low dose ketamine and ondansetron after spinal anesthesia during hernia surgery, as well as the anticipated side effects and complications.

Patients and Methods: This study presents a prospective randomized single blinded study. After obtaining approval from the medical ethical committee of Ain Shams University, this study was conducted in Ain Shams University hospitals operating rooms. Study period was from January 2018 to May 2018.

Results: Our results indicated that low dose ketamine and ondansetron were effective, with more extent to ketamine, in prevention of post spinal shivering in patients undergoing hernia surgery and these results agreed with other results of studies done before.

Conclusion: Our results indicated that Prophylactic low dose ketamine $(0.25 \mathrm{mg} / \mathrm{kg})$ and Ondansetron $(4 \mathrm{mg})$ significantly decreased shivering in patients undergoing spinal anesthesia without significant side effects. Ketamine found to be more effective in controlling post spinal shivering.

Keywords: Hernia Surgeries - Anesthesia - Ondansetron - Prophylactic

\section{INTRODUCTION}

Shivering is uncomfortable for the patient and may interfere with monitoring of electrocardiogram, blood pressure (BP), and oxygen saturation. It increases oxygen consumption, lactic acidosis and carbon dioxide production. Those effects are particularly bothersome in the surgical population $^{(1)}$.

Regional anesthesia may impair thermoregulatory control and up to a $57 \%$ incidence of shivering during regional anesthesia has been reported. Regional anesthesia produces vasodilatation, which facilitates core-to-peripheral redistribution of heat ${ }^{(2)}$.

Postoperative shivering occurs in 5$65 \%$ of patients recovering from general anesthesia. This may be normal thermoregulatory shivering in response to core hypothermia or may result from the release of cytokines by the surgical procedure. The core temperature usually decreases by $0.5-1.5 \mathrm{c}$ in the first hour after induction of anesthesia. All general anesthetics markedly impair normal thermoregulatory control. However, nonthermoregulatory shivering may also occur in normothermic patients in response to certain anesthetics or postoperative pain ${ }^{(3)}$.

The treatment of shivering includes both pharmacological and nonpharmacological methods. The nonpharmacological management is by external heating like the use of forced air warming, warming blankets, warmed fluids etc., according to the results of a meta-analysis, the most frequently reported pharmacological interventions include clonidine, pethidine, tramadol, nefopam and ketamine ${ }^{(4)}$.

Unfortunately, no gold standard treatment is known for shivering as the 
administration of all the available drugs is associated with various adverse effects.

Recently ketamine and ondansetron have been tried to prevent shivering during anesthesia with good results. Ketamine a competitive NMDA receptor antagonist has a role in thermoregulation at various levels. NMDA receptor modulates noradrenergic and serotoninergic neurons in locus ceruleus. It is used as anti-shivering agent in dose of 0.5$0.75 \mathrm{mg} / \mathrm{kg}$ IV. But even in these doses it causes side effects i.e. drowsiness, hallucination and delirium ${ }^{(5)}$.

Ondansetron is 5-HT3 receptor antagonist, primarily used to prevent emesis. Recently it has also been tried successfully for prevention of shivering in dose of $8 \mathrm{mg}$ IV without any side effects. The mechanism of 5HT3 antagonists in the regulation of body temperature has not been clarified, but it may be related to the inhibition of serotonin uptake on the preoptic anterior hypothalamus region (4).

As there are very few studies in relation to use of prophylactic ketamine and ondansetron for prevention of shivering during spinal anesthesia, So we conducted the present study to evaluate and compare the relative efficacy and safety of low dose ketamine $(0.25$ $\mathrm{mg} / \mathrm{kg}$ ) and ondansetron (4 mg) for prevention of shivering during spinal anesthesia.

\section{PATIENTS AND METHODS}

Type of study: This study presents a prospective randomized single blinded study.

Study setting: After obtaining approval from the medical ethical committee of Ain Shams University, this study was conducted in Ain Shams University hospitals operating rooms.

Study period: Start point: January 2018 - end point: May 2018.

\section{Study population:}

Inclusion Criteria: ASA I, ASA II or ASA III patients, aging 18 to 70 years old with ideal body weight $60-90 \mathrm{Kg}$. The individual cases of surgery involved below umbilicus hernia repair operations (inguinal/femoral/paraumblical) with average time 120-180 mins.

Exclusion Criteria: Patient refusal, ASA IV patients, age less than 18 or more than 70 years old, ideal body weight less than 60 or more than $90 \mathrm{Kg}$, procedure duration more than 3 hour, complicated procedure and massive blood loss and transfusion. Contraindication to regional anesthesia like: coagulopathies, infection at injection site, hypovolemia. Contraindications for using Ondansetron and ketamine (Allergic reactions/hypersensitivity).

Sampling method: The patients randomly divided into two groups: Group (K) and Group $(\mathrm{O})$ by using computer generated numbers (CGN) with sealed envelopes handed to third party blinded to treatment assignment.

Sample size: 30 patients scheduled for surgical repair of hernia.

\section{Study groups:}

The patients were randomly assigned into two groups: Group $\mathrm{K}(\mathrm{n}=15)$ : received $0.25 \mathrm{mg} / \mathrm{kg}$ IV ketamine. Group O $(\mathrm{n}=15)$ : received $4 \mathrm{mg}$ IV ondansetron.

\section{Ethical considerations:}

This study was done after obtaining approval from ethical committee of Ain Shams University Hospitals operating rooms. It included adult patients undergoing hernia surgeries. A written consent was obtained from every patient after explaining the study protocol and taking their consent to the type of anesthesia and surgical procedure.

\section{Study procedures}

Preoperative settings: Preoperative assessment was done to all the patients who were going to join this study before reaching the pre-induction room.

The assessment included: History taking (especially drug allergies and 
coagulopathies). Full examination, checking the full lab results and radiographs studies. Checking any kind of medications that any of the patients takes. On reaching the preinduction room, the following was done for each of the patients included in the current study: Inserting a secured wide bore I.V. access in a sterile technique. Antibiotic was given I.V. after sensitivity test had been done. Attaching a monitor (pulse oximetry, noninvasive blood pressure "NIBP", three leads or five leads ECG) till the patient entered the OR with recording the initial vital data.

Intraoperative settings: Upon arrival of the patient to OR, basic monitoring (NIBP, pulse oximeter) was attached. Preload with $500-1000 \mathrm{ml}$ of ringer's solution had been given. The temperature of operating room was maintained at $24-26^{\circ} \mathrm{C}$ with the help of air conditioner temperature setting. Axillary temperature was measured with the help of axillary thermometer and all the patients were covered with standard single blanket. Spinal anesthesia was performed in the sitting position, either with midline or paramedian approach at the L3-4 or L4-5 level, with a 25G Quincke spinal needle. Subcutaneous infiltration with 2-3 $\mathrm{ml}$ of $1 \%$ lidocaine at site of spinal needle insertion was done after skin preparation and under complete aseptic technique. Once free flow of clear CSF is obtained, a $25 \mathrm{mcg}$ fentanyl loaded in $5 \mathrm{ml}$ syringe was injected intrathecally with a hyperbaric bupivacaine $0.5 \%$. The dose of bupivacaine was adjusted according to parturients height. After intrathecal injection, patients immediately returned supine supplemented with oxygen $2 \mathrm{~L} / \mathrm{min}$ via a nasal cannula and three or five lead ECG was attached. Dermatomal level of sensory block was determined with hot-cold or pinprick tests; T6 is the targeted level before surgical incision. Each group was given the same anesthetic management.

The patients were randomly divided into two groups:

Group K: Received $0.25 \mathrm{mg} / \mathrm{kg}$ IV ketamine. Group $O$ : Received $4 \mathrm{mg}$ IV ondansetron.

Just after the intrathecal injection, one of the study drugs (Ondansetron $4 \mathrm{mg}$ / Ketamine $0.25 \mathrm{mg} / \mathrm{kg}$ ) was given as IV bolus.

Shivering was recorded at 15 minutes interval, and degree of shivering was assessed. This could be done according to: Bedside Shivering Assessment Scale (BSAS).

Side effects i.e. hypotension, nausea and vomiting, sedation and hallucinations were also recorded.

The procedures were conducted in the operating theatre with all equipment and drugs of resuscitation and general anesthesia ready.

In the recovery room also all patients were monitored, received oxygen through facemask and were covered with woolen blanket. Patient with nausea and vomiting were treated with metoclopramide $10 \mathrm{mg}$. Pethidin in hand for controlling sever degrees of shivering.

\section{Statistical analysis:}

Recorded data were analyzed using the statistical package for social sciences, version 20.0 (SPSS Inc., Chicago, Illinois, USA). Quantitative data were expressed as mean \pm standard deviation (SD). Qualitative data were expressed as frequency and percentage. 


\section{RESULTS}

Table 1: Comparison between ketamine group $\mathrm{K}$ and Ondansetron group $\mathrm{O}$ according to demographic data.

\begin{tabular}{|c|c|c|c|c|}
\hline Demographic Data & $\begin{array}{c}\text { Group K } \\
(\mathrm{N}=15)\end{array}$ & $\begin{array}{c}\text { Group } 0 \\
(\mathrm{~N}=15)\end{array}$ & $t / x 2 \#$ & p-value \\
\hline Age (years) & $39.86 \pm 10.23$ & $42.98 \pm 9.29$ & 0.974 & 0.498 \\
\hline \multicolumn{5}{|l|}{ Gender } \\
\hline Male & $8(53.3 \%)$ & $9(60.0 \%)$ & $1.021 \#$ & 0.294 \\
\hline Female & $7(46.7 \%)$ & $6(40.0 \%)$ & & \\
\hline Weight (kg) & $47.78 \pm 6.73$ & $48.58 \pm 6.37$ & 1.013 & 0.458 \\
\hline Height (cm) & $142.08 \pm 4.25$ & $141.04 \pm 3.15$ & 0.962 & 0.435 \\
\hline \multicolumn{5}{|l|}{ ASA } \\
\hline I & $11(73.3 \%)$ & $9(60.0 \%)$ & \multirow{3}{*}{$0.676 \#$} & \multirow{3}{*}{0.713} \\
\hline II & $3(20.0 \%)$ & $4(26.7 \%)$ & & \\
\hline III & $1(6.7 \%)$ & $2(13.3 \%)$ & & \\
\hline Median level of sensory block (dermatome) & T6 (T5-T6) & T6 (T5-T6) & 0.000 & 1.000 \\
\hline
\end{tabular}

t-Independent Sample t-test; \#x2- Chi-square test

p-value $>0.05 \mathrm{NS}$; *p-value $<0.05 \mathrm{~S} ; *$ p-value $<0.001 \mathrm{HS}$

This table shows no statistically significant difference between groups according to demographic data.

Table 2: Comparison between ketamine group and Ondansetron group according to axillary temperature $\left({ }^{\circ} \mathrm{C}\right)$

\begin{tabular}{|l|c|c|c|c|}
\hline \multicolumn{1}{|c|}{$\begin{array}{c}\text { Axillary temperature } \\
\left({ }^{\circ} \mathbf{C}\right)\end{array}$} & Group K (N=15) & Group O $(\mathbf{N}=\mathbf{1 5})$ & t-test & p-value \\
\hline At 0 min. & $36.45 \pm 0.77$ & $36.40 \pm 0.76$ & 0.770 & 0.380 \\
\hline At 10 min. & $36.60 \pm 0.92$ & $36.45 \pm 0.91$ & 2.310 & $0.009^{*}$ \\
\hline At 20 min. & $36.80 \pm 0.77$ & $36.50 \pm 0.77$ & 4.620 & $0.010^{*}$ \\
\hline At 30 min. & $36.85 \pm 0.74$ & $36.55 \pm 0.73$ & 4.620 & $0.012^{*}$ \\
\hline At 40 min. & $36.85 \pm 0.77$ & $36.55 \pm 0.77$ & 4.620 & $0.008^{*}$ \\
\hline At 50 min. & $36.90 \pm 0.92$ & $36.55 \pm 0.91$ & 5.390 & $0.009^{*}$ \\
\hline At 60 min. & $36.85 \pm 0.70$ & $36.55 \pm 0.69$ & 4.620 & $0.007^{*}$ \\
\hline At 70 min. & $36.80 \pm 0.92$ & $36.35 \pm 0.91$ & 6.930 & $0.008^{*}$ \\
\hline At 80 min. & $36.75 \pm 0.81$ & $36.45 \pm 0.80$ & 4.620 & $0.012^{*}$ \\
\hline At 90 min. & $36.70 \pm 0.92$ & $36.40 \pm 0.91$ & 4.620 & $0.008^{*}$ \\
\hline At 100 min. & $36.65 \pm 0.77$ & $36.35 \pm 0.76$ & 4.620 & $0.013^{*}$ \\
\hline At 110 min. & $36.60 \pm 0.92$ & $36.30 \pm 0.91$ & 4.620 & $0.016^{*}$ \\
\hline At 120 min. & $36.50 \pm 0.84$ & $36.25 \pm 0.83$ & 3.850 & $0.014^{*}$ \\
\hline
\end{tabular}

t-Independent Sample t-test

p-value $>0.05 \mathrm{NS}$; *p-value $<0.05 \mathrm{~S}$

This table shows statistically significant difference between groups according to axillary temperature $\left({ }^{\circ} \mathrm{C}\right)$ from at $10 \mathrm{~min}$ to at $120 \mathrm{~min}$. 
Table 3: Comparison between groups according to MBP ( $\mathrm{mmHg}$ )

\begin{tabular}{|l|c|c|c|c|}
\hline \multicolumn{1}{|c|}{ MBP (mmHg) } & Group K $(\mathbf{N}=15)$ & Group O $(\mathbf{N}=15)$ & t-test & p-value \\
\hline At 0 min. & $95.48 \pm 7.64$ & $96.48 \pm 7.72$ & 0.886 & 0.274 \\
\hline At 10 min. & $99.76 \pm 7.66$ & $95.98 \pm 8.16$ & 4.967 & $0.015^{*}$ \\
\hline At 20 min. & $102.51 \pm 8.20$ & $95.48 \pm 7.64$ & 5.313 & $0.017^{*}$ \\
\hline At 30 min. & $101.82 \pm 8.23$ & $93.47 \pm 8.32$ & 5.313 & $0.021^{*}$ \\
\hline At 40 min. & $99.50 \pm 8.04$ & $93.45 \pm 7.24$ & 5.313 & $0.014^{*}$ \\
\hline At 50 min. & $95.50 \pm 7.96$ & $92.44 \pm 7.08$ & 0.809 & 0.378 \\
\hline At 60 min. & $95.40 \pm 7.80$ & $90.44 \pm 7.52$ & 0.693 & 0.294 \\
\hline At 70 min. & $94.51 \pm 7.72$ & $89.45 \pm 7.16$ & 1.04 & 0.336 \\
\hline At 80 min. & $94.28 \pm 7.64$ & $89.35 \pm 7.16$ & 0.693 & 0.504 \\
\hline At 90 min. & $93.52 \pm 7.56$ & $89.40 \pm 7.60$ & 0.693 & 0.336 \\
\hline At 100 min. & $92.46 \pm 7.40$ & $90.45 \pm 7.24$ & 0.693 & 0.546 \\
\hline At 110 min. & $91.54 \pm 7.32$ & $90.45 \pm 8.05$ & 0.693 & 0.672 \\
\hline At 120 min. & $90.45 \pm 7.24$ & $88.44 \pm 7.08$ & 0.578 & 0.588 \\
\hline
\end{tabular}

t-Independent Sample t-test

p-value $>0.05 \mathrm{NS}$; *p-value $<0.05 \mathrm{~S}$

This table shows statistically significant difference between $\mathrm{K}$ and $\mathrm{O}$ groups according to MBP from at $10 \mathrm{~min}$ to at $40 \mathrm{~min}$.

Table 4: Comparison between groups according to heart rate (BPm)

\begin{tabular}{|l|c|c|c|c|}
\hline \multicolumn{1}{|c|}{ Heart Rate (bpm) } & Group K (N=15) & Group O (N=15) & t-test & p-value \\
\hline At 0 min. & $81.24 \pm 6.50$ & $80.24 \pm 6.42$ & 0.339 & 0.274 \\
\hline At 10 min. & $84.25 \pm 6.74$ & $80.74 \pm 6.86$ & 3.326 & $0.016^{*}$ \\
\hline At 20 min. & $87.26 \pm 6.98$ & $81.24 \pm 6.50$ & 6.653 & $0.018^{*}$ \\
\hline At 30 min. & $86.26 \pm 6.90$ & $80.74 \pm 7.19$ & 6.653 & $0.022^{*}$ \\
\hline At 40 min. & $84.25 \pm 6.74$ & $80.24 \pm 6.42$ & 1.571 & 0.270 \\
\hline At 50 min. & $83.25 \pm 6.66$ & $79.24 \pm 6.34$ & 1.833 & 0.303 \\
\hline At 60 min. & $80.24 \pm 6.42$ & $77.23 \pm 6.56$ & 1.571 & 0.236 \\
\hline At 70 min. & $79.24 \pm 6.34$ & $77.73 \pm 6.22$ & 2.356 & 0.270 \\
\hline At 80 min. & $77.73 \pm 6.22$ & $78.23 \pm 6.26$ & 1.571 & 0.405 \\
\hline At 90 min. & $77.23 \pm 6.18$ & $77.73 \pm 6.61$ & 1.571 & 0.270 \\
\hline At 100 min. & $75.23 \pm 6.02$ & $77.23 \pm 6.18$ & 1.571 & 0.438 \\
\hline At 110 min. & $74.72 \pm 5.98$ & $76.23 \pm 6.78$ & 1.571 & 0.540 \\
\hline At 120 min. & $74.22 \pm 5.94$ & $75.23 \pm 6.02$ & 1.309 & 0.472 \\
\hline
\end{tabular}

t-Independent Sample t-test

p-value $>0.05 \mathrm{NS}$; $*$ p-value $<0.05 \mathrm{~S}$

This table shows statistically significant difference between $\mathrm{K}$ and $\mathrm{O}$ groups according to heart rate from at $10 \mathrm{~min}$ to at $30 \mathrm{~min}$.

Table 5: Comparison between $\mathrm{K}$ and $\mathrm{O}$ groups according to shivering score

\begin{tabular}{|c|c|c|c|c|}
\hline Shivering score & Group K (N=15) & Group O (N=15) & x2 & p-value \\
\hline 0 & $13(86.7 \%)$ & $8(53.3 \%)$ & & \multirow{2}{*}{0.017} \\
\cline { 1 - 3 } 0 & $1(6.7 \%)$ & $4(26.7 \%)$ & \multirow{2}{*}{$0.046^{*}$} \\
\hline 2 & $1(6.7 \%)$ & $2(13.3 \%)$ & & \\
\hline 3 & $0(0.0 \%)$ & $1(6.7 \%)$ & & \\
\hline
\end{tabular}

x2- Chi-square test; *p-value $<0.05 \mathrm{~S}$

This table shows statistically significant difference between groups according to shivering score. 
Table 6: Comparison between $\mathrm{K}$ and $\mathrm{O}$ groups according to hypotension, nausea and vomiting and sedation

\begin{tabular}{|l|c|c|c|c|}
\hline & Group K (N=15) & Group O (N=15) & x2 & p-value \\
\hline Hypotension & $2(13.3 \%)$ & $7(46.7 \%)$ & 4.552 & $0.039^{*}$ \\
\hline Nausea and vomiting & $3(20.0 \%)$ & $1(6.7 \%)$ & 0.285 & 0.593 \\
\hline Sedation & $14(93.3 \%)$ & $0(0.0 \%)$ & 22.470 & $<0.001^{* *}$ \\
\hline
\end{tabular}

$\mathrm{x} 2$ - Chi-square test

p-value >0.05 NS; *p-value <0.05 S; *p-value <0.001 HS

This table shows statistically significant difference between $\mathrm{K}$ and $\mathrm{O}$ groups according to hypotension and sedation.

\section{DISCUSSION}

Shivering is not only distressing to patients, but can lead to physiological changes such as increased tissue oxygen consumption and carbon dioxide production, resulting in raised minute ventilation and cardiac output. It also interferes with patient monitoring and increase the sensation with surgical pain postoperative.

There are three reasons for developing hypothermia under spinal anesthesia. First, spinal anesthesia leads to an internal redistribution of heat from the core to the peripheral compartment. Redistribution of core temperature during regional anesthesia is typically restricted to the lower extremity. Second, with loss of thermoregulatory vasoconstriction below the level of the spinal blockade, there is increased heat loss from body surfaces of the patient. Last, there is altered thermoregulation under spinal anesthesia characterized by a $0.5^{\circ} \mathrm{C}$ decrease in vasoconstriction and shivering thresholds and a slight increase in the sweating threshold (6).

In our study we investigated the comparative efficacy and safety of prophylactic low dose of ondansetron and ketamine (with different mechanism of action) for prevention of shivering during spinal anaesthesia. The median level of sensory block after 15 minutes of spinal anesthesia was comparable (up to T6) in both of the study groups.

Hemodynamic parameters like heart rate, systolic blood pressure, diastolic blood pressure and mean arterial pressure were monitored every 10 minutes throughout intraoperative period. Nearly, there was no difference among the 2 groups in relation to hemodynamic parameters. These results were consistent with previous studies by Sagir et al. ${ }^{(5)}$ and Kelsaka et al. ${ }^{(7)}$.

The axillary temperature decreased significantly after spinal anesthesia in both groups with respect to baseline values. This is expected because hypothermia occurs during spinal anesthesia due to internal redistribution of body heat, heat loss to environment and inhibition of centrally mediated thermoregulatory control. In this study Axillary temperature decreased significantly in ondansetron than in ketamine group. $\mathrm{P}$ value was found to be significant $(\mathrm{p}<0.05)$ at every measurement between ketamine and ondansetron groups.

In this study, shivering was graded using Bedside Shivering Assessment Scale (BSAS) ${ }^{(8)}$. The prophylactic drug was considered ineffective if the patient shivered to grade 3 and pethidine $0.5 \mathrm{mg} / \mathrm{kg}$ IV was given to control the shivering. Sagir et al. ${ }^{(5)}$, in their study used same protocol. In our study, no premedication was used. In the study of Kelsaka et al. ${ }^{(7)}$, 10mg of diazepam was used as premedication. In the study of Sagir et al. ${ }^{(5)}$, no premedication also was used.

Ondansetron, which is a specific 5HT3 receptor antagonist, is widely used antiemetic drug. The recommended doses of ondansetron for prevention of postoperative nausea \& vomiting are 4-8 $\mathrm{mg}$ in adult patients. Kelsaka et al. ${ }^{(7)}$ compared the $8 \mathrm{mg}$ ondansetron with pethidine for prevention of shivering and found the same antishivering effect and the incidence of shivering was $8 \%$ in ondansetron group. In our study, low dose of ondansetron (4mg) was used and the incidence of shivering was $46.7 \%$ in the ondansetron group.

Very few studies are available till date in relation to use of ketamine for prevention of 
shivering during general or regional anesthesia probable because of its undesirable side effects like too much sedation, hallucination and nausea and vomiting.

Sagir et al. ${ }^{(5)}$ showed that $0.5 \mathrm{mg} / \mathrm{kg}$ of ketamine was also effective in prevention of shivering during spinal anesthesia. In our study, very low dose of ketamine $(0.25 \mathrm{mg} / \mathrm{kg})$ was used to minimize the side effect and we found that it was significantly effective and the shivering was observed in only $13.4 \%$ in ketamine group.

Sedative effect was present for the first 30 minutes of intraoperative period. This was obvious finding in ketamine group because ketamine in low dose has sedative effect but there was lesser grade of sedation with dose of $0.25 \mathrm{mg} / \mathrm{kg}$. Sagir et al. ${ }^{(5)}$ used $0.5 \mathrm{mg} / \mathrm{kg}$ of ketamine and sedation grade was 3 in most patients. This mild sedation observed may be an advantage during surgery under spinal anesthesia as it avoids the need of giving other sedative or anxiolytic drug like midazolam. The other significant finding of our study was that no hallucination was seen with $0.25 \mathrm{mg} / \mathrm{kg}$ of ketamine which was observed in previous study with higher doses. As regard nausea and vomiting, nearly there was no difference among the two study groups. But it is a little with ondansetron group. Nausea in this study was treated with IV metoclopramide $10 \mathrm{mg}$.

In the present study, when the effectiveness of ondansetron and ketamine was compared, ketamine was found to be more effective in prevention of shivering. The hypotensive episode was also found to be less in ketamine as compared to ondansetron group. In our cases, hypotension was managed with $6 \mathrm{mg}$ of IV ephedrine.

Our results also did not coincide with those of Browning et al. ${ }^{(9)}$ who evaluated the use of intravenous ondansetron $8 \mathrm{mg}$, before performing combined spinal-epidural anesthesia in women undergoing elective cesarean delivery and concluded that it does not decrease the incidence or severity of shivering.

Kim et al. ${ }^{(10)}$ performed a study to evaluate the effect of ramosetron, another 5HT3 antagonist, on shivering during spinal anesthesia in patients who had undergone knee arthroscopy. Shivering was observed in two patients in group $\mathrm{R}$ (ramosetron) and nine patients in group $\mathrm{S}$ (saline) $(\mathrm{P}=0.038)$. This coincides with our findings.

Our results matched with those found by Sagir et al. ${ }^{(5)}$ who compared placebo, ketamine, granisetron, and a combination of ketamine and granisetron (another member of 5-HT3 antagonists) for the prevention of shivering caused by regional anesthesia in patients undergoing urological surgery. After $15 \mathrm{~min}$, the number of patients with observed shivering was 22 in group $\mathrm{P}$ (placebo group), six in group $\mathrm{G}$ (the group receiving granisetron only), seven in group GK (the group receiving a combination of granisetron and ketamine), and 0 in group $\mathrm{K}$ (the group receiving ketamine only); thus, in their study granisetron significantly decreased shivering in comparison with placebo.

Kelsaka et al. (7), compared ondansetron, meperidine, and placebo for prevention of shivering after spinal anesthesia and in this double-blind study, 75 patients were randomized into three groups and observed that incidence of PAS was $36 \%$ in saline (control) group as compared to $8 \%$ in the group receiving $8 \mathrm{mg}$ ondansetron and $8 \%$ in meperidine group.

In our study, age, sex, and ASA grade distribution of patients were nearly identical in the two groups. We did not observe a change in the core temperature gradient between the two groups. A study with a more prolonged duration of postoperative temperature monitoring is needed to note if core-periphery temperature changes occur with passage of time.

In our study, there was statistically significant difference found between the studied groups regarding age, height, weight and BMI.

Limitations of our study that we considered one segment of populations with special characteristics, only adult patients undergoing hernia surgery under spinal anesthesia. Thus, further studies are needed to evaluate the effects of these drugs on different segments of populations. 


\section{CONCLUSION}

Our results indicate that Prophylactic low dose ketamine $(0.25 \mathrm{mg} / \mathrm{kg})$ and Ondansetron (4mg) significantly decreased shivering in patients undergoing spinal anesthesia without significant side effects. Ketamine found to be more effective in controlling post spinal shivering.

\section{REFERENCES}

1. Torossian A (2013): Perioperative thermal management in children. Anasthesiol Intensivmed Notfallmed Schmerzther., 48(4): 278-80.

2. Honarmand A, Safavi M, Dadkhah S et al. (2015): The effects of different doses of intrathecal meperidine on the incidence and severity of shivering during lower extremity orthopedic surgery under spinal anesthesia: a randomized, placebo-controlled, double blind-clinical trial. Adv Biomed Res., 4: 3.

3. Pazderska A, O'Connell M, Pender N et al. (2013): Insights into thermoregulation: a clinico-radiological description of Shapiro syndrome. J Neurol Sci., 329(1-2): 66-8.

4. Park SM, Mangat HS, Berger $\mathrm{K}$ et al. (2012): Efficacy spectrum of antishivering medications: meta-analysis of randomized controlled trials. Crit Care Med., 40(11): 3070-82.

5. Sagir O, Gulhas $\mathrm{N}$, Toprak $\mathrm{H}$ et al. (2007): Control of shivering during regional anaesthesia: Prophylactic ketamine and granisetron. Acta Anaesthesiol Scand., 51: 44-9.

6. Dal D, Kose A, Honca $M$ et al. (2005): Efficacy of prophylactic ketamine in preventing postoperative shivering. $\mathrm{Br} \mathrm{J}$ Anaesth., 95(2): 189-92.

7. Kelsaka E, Baris S, Karakaya D et al. (2006): Comparison of ondansetron and meperidine for prevention of shivering in patients undergoing spinal anesthesia. Reg Anesth Pain Med., 31: 40- 5.

8. Olson DM, Grissom JL, Williamson RA et al. (2013): Inter rater reliability of the bedside shivering assessment scale, American Journal Critical Care, 22: 7075.

9. Browning RM, Fellingham WH, O'Loughlin EJ et al. (2013): Prophylactic ondansetron does not prevent shivering or decrease shivering severity during cesarean delivery under combined spinal epidural anesthesia. Reg Anesth Pain Med., 38: 38-43.

10. Kim MS, Kim DW, Woo SH et al. (2010): Effect of ramosetron on shivering during spinal anesthesia. Korean $\mathbf{J}$ Anesthesiol., 58: 256-259 